\begin{tabular}{|c|c|c|}
\hline $\begin{array}{l}\text { SUCRS } \\
\text { PUCR }\end{array}$ & $\begin{array}{l}\text { ESCOLA DE } \\
\text { HUMANIDADES }\end{array}$ & $\begin{array}{l}\text { Revista de Filosofia da PUCRS } \\
\text { Veritas, Porto Alegre, v. } 65 \text {, n. 1, p. 1-11, jan.-mar. } 2020 \\
\text { e-ISSN: } 1984-6746 \text { | ISSN-L: 0042-3955 }\end{array}$ \\
\hline do $h t t p: / / d x$. & $\mathrm{rg} / 10.15448 / 1984-6746.2020 .1 .36679$ & \\
\hline
\end{tabular}

SEÇÃO: VARIA

\title{
Crítica da tecnologia como metafísica: reflexão sobre a narrativa pós-natureza do antropoceno
}

\author{
Critique of technology as metaphysics: reflection on the post-nature \\ narrative of the Antropocene \\ Crítica de la tecnología como metafísica: reflexión sobre la narrativa \\ post-naturaleza del antropoceno
}

\section{Tales Tomaz ${ }^{1}$}

orcid.org/0000-0002-5492-2727

tales.tomaz@sbg.ac.at

Recebido em: 19 dez. 2019 Aprovado em: 31 dez. 2019 Publicado em: 12 mai. 2020

\section{(c) (1)}

Artigo está licenciado sob forma de uma licença Creative Commons Atribuição 4.0 Internacional.
Resumo: Este texto propõe uma critica da tecnologia conforme abordada na narrativa pós-natureza do antropoceno. Para essa narrativa, também chamada de pós-ambientalismo, o antropoceno é o momento histórico em que fica clara a impossibilidade de uma noção idealizada da natureza, distinta da intervenção humana. Neste texto, argumenta-se que, embora tenha méritos no questionamento de aspectos cruciais do pensamento moderno, essa narrativa tem também problemas teórico-conceituais significativos derivados da centralidade atribuida à mediação técnica, que acaba convertendo-a em uma espécie de metafísica. A exposição das teses da narrativa pós-natureza do antropoceno se dá a partir do diálogo com textos de ativistas do pós-ambientalismo, como Michael Shellenberger e Ted Nordhaus, e de pensadores que fornecem a essa corrente o fundamento teórico-conceitual, como Bruno Latour e Peter Sloterdijk. A crítica se ampara na argumentação dos filósofos contemporâneos Dieter Mersch e Andreas Luckner. que desdobram ideias já sinalizadas por Martin Heidegger e indicam caminhos para compreender os limites de perspectivas metafísicas sobre tecnologia.

Palavras-chave: Tecnologia. Metafísica. Antropoceno. Pós-ambientalismo.

Abstract: This text proposes a critique of technology as addressed in the post-nature narrative of the Anthropocene. Within this narrative, also called post-environmentalism, Anthropocene is the historical moment in which the impossibility of an idealized notion of nature - distinct from human intervention - becomes clear. In this text, it is argued that, although questioning crucial aspects of modern thought, this narrative also has significant theoretical-conceptual problems derived from the centrality attributed to technological mediation, which eventually turns it into a kind of metaphysics. The exposition of the post-nature arguments comes from the dialogue with texts of post-environmental activists, such as Michael Shellenberger and Ted Nordhaus, and from scholars who provide post-environmentalists with theoretical and conceptual background, such as Bruno Latour. and Peter Sloterdijk. The critique draws on the arguments of the contemporary philosophers Dieter Mersch and Andreas Luckner, who unfold ideas already introduced by Martin Heidegger and point to the shortcomings of metaphysical perspectives on technology. Keywords: Technology. Metaphysics. Anthropocene. Post-environmentalism.

Resumen: Este texto propone una crítica de la tecnología tal como se aborda en la narrativa post-naturaleza del antropoceno. Para esta narrativa, también llamada postambientalismo, el antropoceno es el momento histórico en el que está clara la imposibilidad de una noción idealizada de la naturaleza, distinta de la intervención humana. Se argumenta en este texto que, aunque tiene méritos en el cuestionamiento de aspectos cruciales del pensamiento moderno, esta narrativa también tiene importantes problemas teórico-conceptuales derivados de la centralidad atribuida a la mediación técnica, que termina convirtiéndola en una especie de metafísica. La exposición de la tesis de la narrativa post-naturaleza del antropoceno tiene lugar a partir del diálogo con textos de activistas postambien- 
talistas como Michael Shellenberger y Ted Nordhaus, y pensadores que proporcionan a esta corriente la base teórico-conceptual, como Bruno Latour y Peter Sloterdijk. La crítica se basa en la argumentación de los filósofos contemporáneos Dieter Mersch y Andreas Luckner, quienes desarrollan ideas ya marcadas por Martin Heidegger e indican maneras de entender los límites de las perspectivas metafísicas de la tecnología. Palabras clave: Tecnología. Metafísica. Antropoceno. Postambientalismo.

\section{Introdução}

Este texto aborda o tema da tecnologia como metafísica a partir de uma reflexão sobre a chamada narrativa pós-natureza do antropoceno. Baseandose em ideias desenvolvidas por pensadores como Bruno Latour e Peter Sloterdijk, essa narrativa afirma que a condição atual do planeta exige constatar a impossibilidade da ideia de uma natureza idealizada, separada da intervenção humana (BONNEUIL, 2015). O argumento que desenvolvo neste texto é que essa conclusão é alcançada devido à posição privilegiada atribuida à tecnologia - entendida como mediação técnica - no interior dessa narrativa. No entanto, esse procedimento é problemático, uma vez que nela a mediação técnica acaba desempenhando a função de princípio explicativo de todo o real, convertendo-se em metafísica. Isso coloca em xeque a legitimidade das próprias premissas da narrativa pós-natureza do antropoceno, risco que, no final das contas, atinge praticamente todas as tentativas de ontologias pós-humanas - entendidas aqui como ontologias que compreendem a indecidibilidade sobre o estatuto ontológico de humanos e não humanos como equivalente à indiferencialidade entre esses dois coletivos (MERSCH, 2013b, 2016).

Primeiramente, o texto apresenta a narrativa pós-natureza do antropoceno conforme definida por Christophe Bonneuil (2015) e discute sua articulação em textos de Michael Shellenberger, Ted Nordhaus, Bruno Latour e Peter Sloterdijk, considerados os mais sofisticados expoentes dessa perspectiva. Em seguida, o texto argumenta que a mediação técnica tem papel central nessa narrativa, revisitando, especialmente em Latour e Sloterdijk, os fundamentos teóricoconceituais que dão sustentação à noção pósnatureza. ${ }^{2}$ Por fim, o texto recorre aos filósofos contemporâneos Dieter Mersch e Andreas Luckner - que, atualizando ideias já apontadas por Heidegger, dão sequência à discussão sobre a relação entre tecnologia, natureza e metafísica - para interpretar tal centralidade da mediação técnica como metafísica e apontar alguns problemas ontológicos e epistemológicos que esse procedimento teórico acarreta.

\section{Antropoceno e a narrativa pós-natureza}

A ideia de antropoceno ganhou força quando o químico holandês Paul Crutzen popularizou o termo nos anos 1990 com o objetivo de descrever uma nova época geológica a suceder o holoceno. Crutzen e o biólogo Eugene Stoermer (2000, p. 17) afirmam que "parece-nos mais do que apropriado enfatizar o papel central da humanidade na geologia e na ecologia, evidenciado pela proposta de usar o termo 'antropoceno' para a atual época geológica". Como os estudos científicos atestam, as atividades humanas terão um impacto duradouro na Terra. Esse impacto se manifesta principalmente no desequilibrio climático, perturbando a relativa estabilidade herdada do final da última era do gelo, há cerca de 12 mil anos, quando costuma-se situar o início do holoceno. As consequências podem ser aterradoras. Para Crutzen (2002, p. 23), isso significa que "uma tarefa assustadora está diante de cientistas e engenheiros, a de orientarem a sociedade para uma gestão ambientalmente sustentável durante a era do antropoceno".

Em resumo, ao propor uma nova compreensão para a fase atual do planeta, Crutzen argumenta que a humanidade desempenha um papel central tanto nas mudanças que aconteceram - o desequilibrio ambiental - quanto nas necessárias mudanças por vir - para restaurar uma certa

\footnotetext{
2 Isso significa que, embora Latour e Sloterdijk tenham uma vasta produção sobre diversos tópicos - muitas vezes em sentidos múltiplos, o que dificulta a sistematização do seu pensamento a respeito do tema -, aborda-se aqui apenas textos que reforçam a concepção pós-natureza, uma vez que não é objetivo do texto uma crítica tout court à obra dos referidos autores, mas apenas a indicação de premissas problemáticas em alguns dos seus desenvolvimentos.
} 
estabilidade sustentável. Daí nomear a época como antropoceno, isto é, a Era do Homem.

Como Christophe Bonneuil (2015) bem coloca, o antropoceno está longe de ser exclusivamente uma narrativa, mas é narrativa também. Ou seja, trata-se não apenas de elencar dados "neutros", mas também de contar uma história sobre "como chegamos até aqui". Para Bonneuil, as abordagens do antropoceno podem ser divididas em pelo menos quatro grandes narrativas, sendo a de Crutzen a narrativa mainstream, que apresenta características típicas do pensamento moderno: 0 triunfo da razão sobre a ignorância; o domínio do ser humano como espécie sobre a natureza; ciência e tecnologia como ferramentas para a realização desses objetivos. É uma narrativa, portanto, que tem mais apelo a partir de uma compreensão que atribui objetividade à ciência e à tecnologia como modos de relação com a natureza.

Entretanto, os desdobramentos do pensamento ocidental no século 20 colocaram concepções modernas cada vez mais sob suspeita. Daí a abertura de espaço para perspectivas concorrentes, como a que Bonneuil (2015) chama de narrativa pósnatureza ou pós-ambientalista. Para essa narrativa, as compreensões tradicionais do antropoceno falham ao continuar entendendo a natureza como uma entidade com existência objetiva, à qual se opõem a ação humana, a cultura, a ciência e a tecnologia. Nesse enquadramento alternativo, o fato de a humanidade ter se tornado um fator geológico significa primariamente que não é possivel mais separar o âmbito humano/social de outros domínios, como o natural (BAMMÉ, 2014). Isso explica, para Shellenberger e Nordhaus (2004, p. 6), que os movimentos ambientalistas tradicionais pouco teriam conquistado nas últimas décadas, apesar de anos "investindo centenas de milhões de dólares no combate ao aquecimento global". As velhas estratégias - fazer lobby para a aprovação de leis que protejam o meio ambiente - funcionaram no passado, mas são cada vez mais associadas com políticas específicas de grupos de interesses. Quando parecem comprometer outros interesses mais imediatos - como a manutenção de empregos, renda e padrão de consumo -. as propostas perdem força e sofrem derrotas políticas, pois um número crescente de pessoas não consegue aceitar o retorno a um estilo de vida frugal e austero. Diante das necessidades ainda maiores e urgentes colocadas pela mudança climática, seria necessária uma visão ecológica mais inspiradora, baseada na ideia de natureza como uma construção social integrada nas nossas próprias intervenções socioeconômicas e tecnoculturais. O ambientalismo tradicional reifica o conceito de "meio ambiente", transformado em uma "coisa" da qual nós, humanos, estamos separados. Eles argumentam que, em contrapartida, "os conceitos de 'natureza' e 'meio ambiente' foram completamente desconstruidos" nas últimas décadas (SHELLENBERGER; NORDHAUS, 2004, p. 12).

A crítica à ideia de natureza idealizada não é nova. Talvez umas das argumentações mais contundentes e marcantes nesse sentido seja a do pensador francês Bruno Latour em Jamais fomos modernos (1993). Para ele, a dissociação dos domínios humano/social e natural é uma consequência da dicotomia sujeito-objeto característica do pensamento moderno. Entretanto, para Latour, essa dicotomia já teria sido colocada em xeque ao longo do século 20, o que nos permitiria ver que a distinção essencial entre os domínios humano/social e natural também é fictícia. Como exemplos, ele questiona: o buraco na camada de ozônio é um fenômeno social ou natural? As estratégias das empresas são fenômenos sociais ou naturais? Não seria possivel mais distinguir e definir dessa forma. "O buraco na camada de ozônio é social demais e também narrado demais para ser verdadeiramente natural; a estratégia das indústrias e dos chefes de Estado está cheia demais de reações químicas para ser reduzida a poder e interesse" (LATOUR, 1993, p. 6).

A concepção da natureza como algo separado se sustentava enquanto não havia nenhum efeito colateral significativo da intervenção humana e "a Natureza permanecia remota e sob controle", quando "a Natureza parecia estar mantida em reserva, transcendente, inesgotável, suficientemente distante" (LATOUR, 1993, p. 50). Em sentido semelhante, Peter Sloterdijk (2011, 
p. 99) afirma que a natureza parecia ser "um Fora ilimitadamente resiliente", que ignorava e absorvia toda intervenção humana. Entretanto, o próprio desenvolvimento da modernidade teria provocado um curto circuito na distinção entre "natureza" e "social". A modernidade teria produzido incontáveis hibridos inclassificáveis, como o buraco na camada de ozônio sugerido por Latour. Por isso, em vez de separar as coisas claramente em domínios - sujeito e objeto, humano/social e natureza -, estariamos diante da necessidade de reconhecer o hibridismo como condição básica das coisas e uma consequente simetria entre humanos e não humanos no social.

Em vez de pressupor uma essência nas coisas que nos habilitaria a distingui-las, classificálas e hierarquizá-las ontologicamente - o que justificaria essências diferentes para humanos e não humanos -, só seria possivel pensar as coisas em suas permanentes relações umas com as outras, ou seja, a partir do que elas fazem. "Essência é existência, e existência é ação", dizia Latour (1994, p. 33). Seguindo uma linha semelhante, Andrew Pickering (1995, p. 6) afirma que o mundo é um lugar preenchido "não com fatos e observações, mas com agência. $O$ mundo, quero dizer, está continuamente fazendo coisas, coisas que atuam sobre nós não como declarações de observação em intelectos desencarnados, mas como forças sobre seres materiais." Isso significa que aquilo que as coisas fazem é anterior a qualquer definição delas e, na realidade, é a única forma pela qual podemos chegar a conhecê-las. Daí considerar a agência como a qualidade fundamental de tudo o que conhecemos, e não apenas dos humanos. A modernidade teria atribuido agência apenas a humanos, diferenciando-os fundamentalmente da natureza dita inanimada. Mas, na concepção pós-natureza, essa posição seria atualmente insustentável. O humano não é um domínio separado da natureza porque, no final, o que caracteriza ambos é a agência, isto é. a possibilidade de se tornarem actantes na rede de eventos do mundo.

O antropoceno passa a ser visto não como o triunfo do humano sobre a natureza nem como a vingança da natureza sobre o humano, mas como a definitiva hibridização desses dois domínios - o humano e o natural -, a impossibilidade de separarmo-los ontologicamente. Para Latour (2014. p. 3). é a época em que "a Terra já retomou todas as características de um ator de pleno direito". Ao reagir às intervenções humanas, a natureza agora exige que abandonemos a concepção objetivista e reconheçamos o emaranhado de actantes em que se constitui a existência e o próprio planeta em si, com agências distribuidas por todos os tipos de entes, e não mais restritas apenas aos humanos. Modificamos a natureza, mas também somos modificados por ela em um processo permanente, de modo que no antropoceno "todos os agentes compartilham o mesmo destino que modifica a forma" (LATOUR, 2014, p. 15).

Na narrativa pós-natureza, o antropoceno é ainda uma condição que nos força a reconhecer que existe apenas esta Terra e temos que cuidar dela. Na metáfora de Sloterdijk (2011, p. 95), é o momento em que percebemos que habitamos a "nave espacial Terra", "um veículo cósmico suscetivel a desordem". 3 Para Sloterdijk, um ponto crucial para essa virada foi a chegada da era espacial, que teria relegado todas as tradições e conhecimentos anteriores ao lugar de mitos. Todos eles ainda estavam ligados a uma concepção pré-astronáutica da Terra e. portanto, teriam pouco a contribuir para nos ajudar a gerenciar a "nave espacial Terra" e seus desafios ambientais (SLOTERDIJK, 2011, p. 96). No antropoceno, nos damos conta de que a natureza não é mais um "Fora ilimitadamente resiliente". Para Koyré (2006), a revolução copernicana havia nos levado de um mundo fechado para um universo infinito, ao tirar a Terra do centro do universo e indicar que o cosmos era muito mais amplo. $O$ antropoceno seria o retorno ao mundo 
fechado, mas "desta vez sem ordem, sem Deus, sem hierarquia, sem autoridade" (LATOUR, 2014, p. 6). Agora fica claro que há apenas essa Terra à nossa disposição, que por isso precisa ser cuidada. Não haverá salvação de fora.

\section{A tecnologia na narrativa pós-natureza}

Mas, vale frisar, se o planeta deve ser preservado, isso não significa o apego a uma natureza inalterada, intocada. Deve haver um esforço para manter circunstâncias que permitam a vida, e isso significa, para os pós-ambientalistas, mais intervenção e modificação na natureza da forma como a conhecemos.

\begin{abstract}
Os ambientalistas dizem: "De agora em diante, nós deveriamos limitar a nós mesmos." Os pós-ambientalistas exclamam: "De agora em diante, nós deveriamos parar de nos flagelar e assumir explícita e seriamente o que nós temos feito por todo o tempo em uma escala cada vez maior, isto é, intervir, agir, querer, cuidar" (LATOUR, 2011b, p. 26).
\end{abstract}

Portanto, a intervenção humana é uma qualidade que deve ser explicitamente assumida, bem como os hibridismos daí decorrentes. Seria preciso rejeitar uma ilusão não intervencionista, purista. Ao mesmo tempo, não se trata de uma intervenção humana "genérica". As argumentações pós-ambientalistas ressaltam uma forma específica de ação: a ação tecnocientífica. A esse respeito, o sociólogo Arno Bammé (2014. p. 21) talvez seja o mais explicito: "A sintese, a unidade da sociedade mundial é produzida agora pela tecnologia, não pela religião, não pela filosofia". Ele acrescenta: "Com a tecnologia que os humanos desenvolvem, eles modificam não apenas a si mesmos e a sociedade na qual vivem e se comunicam, mas sobretudo o meio ambiente, a base de ambos". Em Jamais fomos modernos, Latour (1993, p. 136, grifo nosso) já indicava caminho semelhante: "Da mesma forma, nós vamos ter que nos transformar profundamente para abrir espaço, hoje, para os não humanos criados pela ciência e pela tecnologia".

Portanto, os hibridismos com os quais lidamos são trazidos à luz pela ciência e pela tecnologia.
Para os pós-ambientalistas, não é possivel viver no antropoceno e rejeitar o papel central do conhecimento tecnocientífico, porque são as próprias criações desse modo de conhecimento que nos dão a sensibilidade necessária para perceber a nossa conexão inextricável com os não humanos, incluindo a natureza. "É apenas porque o navio de Magalhães retornou que seus contemporâneos puderam gravar profundamente em suas mentes a imagem de uma Terra esférica", exemplifica Latour (2013, p. 94), mencionando um produto da técnica. A ciência e os artefatos tecnológicos nos proveem as sensibilidades necessárias para compreender os hibridismos que compõem o real. Em outras palavras, é na ação tecnológica que repousa a chave para entender a condição humana.

As tecnologias são cruciais não apenas na profusão de hibridismos que nos permitem ver a simetria ontológica entre humanos e não humanos. O avanço da tecnociência é considerado ainda a melhor forma de lidar com a possibilidade cada vez mais palpável do colapso climático, condição atingida pela própria produção moderna de hibridismos. Diante do dilema entre "a ética dos fogos de artifício ou a ética do ascetismo", ou seja, entre a aceleração do estilo de vida moderno ou a adoção de um estilo de vida frugal, Sloterdijk (2011, p. 104) sugere que exploremos mais o mesmo modo de conhecimento que desencadeou o colapso climático. Sua justificativa concede um vislumbre revelador sobre a ideia de tecnologia presente em argumentações pós-ambientalistas. Sloterdijk (2011, p. 108) se pergunta: no final das contas, é realmente correto interpretar a Terra como um Uno "não multiplicável"? Afinal, não temos mais apenas a geosfera e a biosfera em seus estados originais, como legadas pela evolução. A tecnosfera e a noosfera - intervenções humanas através da ciência e da tecnologia - foram introduzidas no mundo, e ainda não se sabe até que ponto elas podem transformar a geosfera e a biosfera. "Não está excluido a priori que através delas [tecnosfera e noosfera] surjam efeitos que se assemelhem ao da multiplicação da Terra" 
(SLOTERDIJK, 2011, p. 108). Para confirmar seu ponto de vista, Sloterdijk (2011, p. 108) acrescenta: "A técnica ainda não pronunciou sua palavra final".

Portanto, não apenas não se recrimina a tecnociência pela condição climática instável do antropoceno, como também se vê nela a melhor oportunidade para escapar do drama anunciado. A confiança na tecnociência é tamanha que Latour (2011b, p. 23) chega a ironizar o nosso temor de que o aquecimento global possa acabar com a humanidade ou a vida como a conhecemos: "Hoje podemos nos debruçar no design molecular das bactérias do solo por meio de nossas ciências e tecnologias. Comandamos robôs em Marte. Fotografamos e sonhamos com outras galáxias. E ainda assim tememos que o clima possa nos destruir".

É possivel perceber ecos da noção moderna de ciência e tecnologia na argumentação dos pós-ambientalistas. No entanto, Sloterdijk (2011. p. 102) afirma que a luta atual pelo clima não está mais voltada para dominar a Terra como na modernidade, mas "tem muito mais a ver com a possibilidade de manter o processo civilizatório aberto e garantir a possibilidade de sua continuidade". Da mesma forma, Latour (2011b, p. 28) afirma que "o pecado não é querer ter domínio sobre a Natureza, mas acreditar que esse domínio significa emancipação, e não conexão". O ponto para Latour (2011b, p. 22) seria antes "modernizar a modernização", desconstruindo a narrativa moderna de emancipação da natureza para aceitar uma assim chamada narrativa composicionista, que vê a história como a irreversivel conexão entre humanos e não humanos. Reinterpretando a ficção de Mary Shelley, Latour sugere que o erro do Dr. Frankenstein não foi ter dado vida a uma máquina monstruosa, mas abandoná-la. Só então ela teria se tornado aterrorizadora. Para não incorrer no mesmo erro, temos que abraçar os hibridismos que produzimos por meio da tecnociência, cuidar deles e seguir o nosso destino, que é a contínua produção de mais hibridismos, de mais conexões entre coletivos humanos e não humanos.

\section{Indiferenciação e reducionismo na mediação técnica}

Por mais sedutoras que sejam, essa narrativa e a argumentação sobre o lugar da tecnociência no mundo contemporâneo também apresentam dificuldades teórico-conceituais que precisam ser discutidas. Neste texto, chamo a atenção para os problemas do sentido metafísico dessa narrativa, apoiando-me especialmente nos filósofos contemporâneos Dieter Mersch e Andreas Luckner, que por sua vez tomam teses do filósofo alemão Martin Heidegger e desdobramnas para pensar questões atuais do humano, da tecnologia e da natureza.

Para esse exercício crítico, convém notar primeiramente que tecnologia na argumentação pós-natureza não é uma referência a um instrumento ou equipamento, mas a uma ação, um fazer. Por isso, às vezes Latour prefere empregar o termo mediação técnica, em que técnica é antes adjetivo. Latour (1994, p. 44) reafirma que, mesmo quando empregada como substantivo, "[técnica] não designa uma coisa, mas um modus operandi, uma cadeia de gestos e know-how, provocando algum resultado antecipado". Tecnologia - ou mediação técnica - é, portanto, um modo de fazer coisas. Para explicar melhor o sentido desse modo de lidar com as coisas, Latour ilustra a "mediação técnica" com a figura mitológica de Dédalo, que é capaz de encontrar "soluções onde nenhuma é visivel, usando qualquer expediente à mão" (LATOUR, 1994, p. 41). Ele possui a habilidade de ordenar as coisas de seu entorno para que elas se transformem em outras que ele próprio concebeu. Como observado por Riis (2008, p. 292), a habilidade de Dédalo é, no final das contas, "enquadrar o mundo de acordo com meios e fins e raciocinar em termos de problemas e soluções".

Essa concepção da técnica não é nova. Na verdade, é bastante próxima da technê conforme discutida originalmente pelos gregos, para quem a técnica era um saber capaz de conceber as coisas como meios para fins (MICKLE, 1998). Interpretando Aristóteles, Andreas Luckner (2008, p. 27) explica que "technê é o pensamento subjacente a essas práticas de produção, que 
considera as atividades como um meio para os fins". A técnica transforma as coisas em meios para, dessa forma, garantir a repetibilidade dos fins esperados. É uma forma de ver as coisas como problemas a serem resolvidos. Portanto, a forma básica como Latour, Sloterdijk e outros pósambientalistas descrevem a técnica não diverge do que historicamente se chamou de technê.

Contudo, ver as coisas como meios à disposição para serem mobilizados e rearranjados para outros fins tem também implicações problemáticas. Uma vez que as coisas sejam tratadas como meios, elas perdem autonomia, no sentido da palavra alemã Selbstständigkeit (que também significa autossuficiência). As coisas só têm significado a partir da relação que se forma, um procedimento típico das ontologias relacionais (MERSCH, 2016). De fato, os defensores da narrativa pósnatureza não veem problema nisso, pois para eles a existência só se dá na ação, isto é, nas associações e conexões com outros entes. Se diferentes coletivos executarem a mesma ação - sejam eles humanos ou não humanos precisam ser considerados como equivalentes (ou simétricos, para usar uma terminologia de Latour). O problema é que essa interpretação só é válida quando se observa os entes exclusivamente do ponto de vista da funcionalidade. Entretanto, conforme Dieter Mersch (2013a, p. 15) explica, há outros pontos de vista, como o da materialidade. Dessa perspectiva, nada é equivalente. Como matéria, nenhuma coisa, ação ou prática é igual e repetível. Para funcionarem como meios para fins, para existirem do ponto de vista das agências, as coisas devem perder a singularidade contida na materialidade de sua manifestação e ser niveladas em termos de funções em uma estrutura. Só então a não identidade da matéria é superada pela identidade das funções. De fato, identidade é uma condição necessária para a repetibilidade exigida pelo procedimento técnico.

Portanto, quando as coisas são abordadas como meios para fins, elas não são mais vistas como objetos com singularidade própria derivada da sua materialidade, mas apenas como funções equivalentes em uma estrutura, privadas da sua autonomia (MERSCH, 2013a; LUCKNER, 2008). Ver as coisas exclusivamente como elementos de uma permanente hibridização é retirar delas qualquer possibilidade de serem por si mesmas. Nesse sentido, desmorona também qualquer possibilidade de diferenciação fundamental. É por isso que Latour (2014, p. 14) pode afirmar, por exemplo, que "a Terra não é nem natureza nem máquina". A indiferenciação essencial é precisamente o que ocorre quando as coisas são vistas como meios para fins, e é o caso da natureza e da Terra na narrativa pós-natureza do antropoceno.

Assim, por abraçar a mediação técnica como princípio de interpretação, a narrativa pósnatureza incorpora, em última análise, a ideia de uma natureza privada de seu caráter de alteridade, de domínio autônomo e insondável cuja característica primária é o fato de que ela simplesmente é, seu acontecimento material. Não se trata aqui da defesa do retorno à ideia dicotômica de natureza e social, mas do reconhecimento de que qualquer coisa, incluindo a natureza, se manifesta primeiramente como materialidade, o que apenas posteriormente permite uma abordagem do ponto de vista da funcionalidade. Como Mersch (2007) argumenta, o acontecimento material das coisas, sem qualquer significado, é anterior a toda tentativa de significá-las, de interpretá-las, sendo o que permite a sua significação. Enquanto isso, na ontologia relacional pressuposta na narrativa pós-ambientalista, a natureza passa a existir exclusivamente do ponto de vista da sua agência, ou seja, desempenhando uma função no coletivo de híbridos do antropoceno, já significando algo. Dessa forma, a existência per se da coisa (o "que", seu acontecimento material) deixa de ser seu aspecto mais básico para dar lugar a uma suposta essência (o "o que", uma abstração identitária e funcional). ${ }^{4}$ Portanto, o conceito de tecnologia presente na narrativa pós-natureza do antropoceno não consegue superar o

4 Sobre a diferença entre "que" e "o que" - e sua relação com a questão da autonomia dos entes -, ver Mersch (2007), Luckner (2008, p. 107-123) e Heidegger (1977, p. 46-65) 
essencialismo que é criticado no interior dessa mesma narrativa. Ele apenas muda o conteúdo da essência. Nessa narrativa, a essência das coisas é que elas são híbridas, ou agências que compõem hibridismos. E, como em toda afirmação de uma essência, trata-se de um reducionismo. ${ }^{5}$

Nessa forma de abordar o real, as coisas são reduzidas a meios para fins, artificios temporários. Tudo parece ser artefato tecnológico - construção artificial, portanto -, incluindo a Terra e a natureza em geral. Isso fica explícito quando Sloterdijk (2011, p. 96) fala repetidamente da necessidade de administrar o planeta sem "instruções de operação" confiáveis. Somente quando as coisas são vistas como artefatos e meios para fins é que são necessárias "instruções de operação".

\section{Tecnologia como metafísica}

Mesmo reducionista, a técnica como meio para fins é, sim, uma maneira possivel de abordar as coisas. As coisas podem ser meios. A questão mais problemática na narrativa pós-ambientalista do antropoceno é que a produção tecnológica de híbridos é considerada não apenas uma das possiveis formas de se relacionar com o real, mas a forma mais avançada e, no fim das contas, a única verdadeira. Como já visto, essa narrativa alça o produzir tecnocientífico ao posto de único saber de fato legítimo. Bammé (2014, p. 58) chega ao ponto de sentenciar que "não se trata mais de descobrir verdades sobre a realidade, mas de decidir a realidade das verdades que produzimos". Trata-se da superioridade absoluta da produção tecnológica. Em Sloterdijk (2011, p. 95), a descrição dessa superioridade ganha traços dramáticos:

No passado, foi permitida às pessoas uma grande medida de ignorância em suas navegações, já que o sistema foi projetado para a tolerância de alto grau de desconhecimento humano. No entanto, à medida que os passageiros [da espaçonave Terra] começam a desvendar o mistério de sua condição e, ao usar a técnica, tomar o poder sobre o meio ambiente, a ignorância inicial diminui por todo o sistema até chegar a um ponto em que certas formas de comportamento ignorante não são mais compativeis com a permanência dos passageiros a bordo. O ser-no-mundo da humanidade, do qual a filosofia do século $X X$ falou, revela-se como um ser a bordo de um veículo cósmico suscetivel a desordem.

Os comportamentos não científicos e não tecnológicos são retratados como "ignorância". Ser-no-mundo equivale a estar-a-bordo, e a única maneira "compativel" de lidar com essa condição é empregar a técnica. Ocorre que, nesse raciocínio, a técnica é o próprio modo de conhecimento que desvela a Terra como espaçonave Terra. É, portanto, um raciocínio circular, tautológico. Essa narrativa toma uma maneira especifica de abordar as coisas e a universaliza, destacando-a do seu papel provisório e histórico. Assim, tudo comparece, de fato, à luz desse saber específico. Curiosamente, essa universalização da técnica como chave explicativa do real é precisamente o que Heidegger notava estar em curso e tentou captar com seu conhecido conceito de Gestell. ${ }^{6}$

Na narrativa pós-natureza do antropoceno, a técnica não é uma dentre outras formas de lidar com as coisas. É a realidade universal, a-histórica, que gradualmente está mostrando sua verdade. Por exemplo, Latour (1994, p. 47, grifo do autor) afirma não haver diferença essencial entre os coletivos do passado e os coletivos do presente, surgidos pelo emprego massivo da técnica: "A diferença, porém, é que o último lo coletivo do presente] traduz, atravessa, inscreve e mobiliza mais elementos, mais intimamente conectados, com um tecido social mais finamente entrelaçado do que o anterior". Mais adiante ele acrescenta: "O que aparece simbolicamente nos velhos coletivos é tomado literalmente nos novos" (LATOUR, 1994, p. 48). O raciocinio fica mais claro em outro texto, em que Latour (2011a,

\footnotetext{
5 Por outra via argumentativa, Francisco Rüdiger (2015, p. 140) chega basicamente à mesma conclusão: "[Na teoria ator-rede, de Latour] Em vez de essências, afirma-se que só há hibridos. Ocorre que se tudo é híbrido, híbrido é o nome do ser le da sua essêncial".

6 Vale frisar que Latour frequentemente situa sua abordagem em oposição à de Heidegger, elegendo-o como um dos principais inimigos da compreensão adequada da mediação tecnológica. Entretanto, este texto se alinha com a abordagem de Riis (2008), para quem não há diferença entre seu conceito de técnica e o do filósofo alemão Martin Heidegger exceto pelo fato de o filósofo alemão admitir a historicidade da técnica.
} 
p. 802, grifo do autor) comenta especificamente a digitalização: "O que eu mais gosto nas novas redes é que a expansão da digitalidade tem aumentando enormemente a dimensão material das redes. Quanto mais digital, menos virtual e mais material uma dada atividade se torna." O argumento é claro: a produção de híbridos na contemporaneidade - no antropoceno - não é exatamente uma novidade; ela apenas atualiza, reforça e torna mais visivel o que sempre foi o modo essencial de ser das coisas. É a verdade da civilização que gradualmente está ficando mais evidente, mais "material".

A pergunta é: de que ponto de vista pode-se assegurar que a mediação técnica seja a maneira mais apropriada de descrever o real e nossa relação para com ele? Para tanto, seria necessário se colocar fora dessa própria mediação para ver outras mediações e concluir que ela é a forma mais adequada. Mas isso não seria possivel porque, se as coisas sempre foram hibridas produtos de mediação técnica -, não existe nenhuma maneira de se colocar realmente fora dessa relação. Portanto, essa abordagem reclama um acesso direto às coisas, à verdade dos fatos, sem que possa assumir uma posição para provar sua tese. Latour (1993, p. 78, grifo nosso) diz explicitamente que o propósito de seu argumento é romper com a ficção adotada na modernidade para restaurar o que as coisas sempre foram: "Se simplesmente restaurarmos esse papel mediador a todos os agentes, exatamente o mesmo mundo, composto exatamente pelas mesmas entidades, deixa de ser moderno e torna-se o que nunca deixou de ser, isto é, não moderno."

Assumindo essa concepção de mediação técnica, a narrativa pós-natureza do antropoceno reivindica saber o que as coisas são, ou seja, uma privilegiada posição universal, a-histórica. Trata-se, portanto, da própria metafísica. E, vale lembrar, estar às voltas com a metafísica é adotar um procedimento tautológico que "pressupõe teorias para justificar teorias que, em última instância, trazem à tona definições que, por sua vez, se assentam em intuições sem fundamento" (MERSCH, 2013b, p. 11). É um procedimento que se assenta em "intuições sem fundamento" porque não há como provar suas afirmações, afinal, não há possibilidade de pensar fora da afirmação metafísica - comparando-a com as demais - sem abandoná-la e romper com a sua própria pretendida universalização, ou seja, romper a metafísica como tal. Consequentemente, a metafísica corresponde a "nada mais do que um espelho do conhecimento contingente como historicamente sedimentado e consolidado em função de tradições culturais" (MERSCH, 2013b, p. 11).

Portanto, por mais avançada que seja na tentativa de superar as limitações da concepção moderna de ciência e tecnologia, a argumentação pós-natureza ainda não é capaz de se livrar do traço metafísico característico da modernidade. Ela universaliza uma concepção contingente e histórica de nossa relação com o mundo a ponto de considerar como explicita Sloterdijk - os conhecimentos não científicos e não tecnológicos como "ignorância".

Como pós-ambientalistas entendem que a natureza é uma construção sociotécnica, não costumam apoiar a tese do ascetismo, embora todas as evidências indiquem que não temos à nossa disposição recursos suficientes para dar sequência ao modo de vida iniciado na modernidade e na industrialização. Seria preciso, entendem, manter a marcha do desenvolvimento alimentado pela intervenção tecnocientífica. "O objetivo da ecologia política não pode ser parar de inovar, inventar, criar e intervir. O verdadeiro objetivo precisa ser ter o mesmo tipo de paciência e comprometimento com as nossas criações que o próprio Deus, o Criador, tem" (LATOUR, 2011b. p. 22). À parte a própria referência mística da passagem, essa posição tem implicações radicais para a manutenção das condições de vida, como explicado por Kagan (2013) e Bonneuil (2015). Para este último, a posição dos pós-ambientalistas "normaliza os riscos tecnológicos como parte necessária da condição humana" (BONNEUIL, 2015. p. 26). É o que fica evidente em passagens de pós-ambientalistas como esta:

A aparição de consequências como o aquecimento global é tomada como uma contradição [da intervenção tecnocientífical, ou mesmo como uma mons- 
truosidade, e obviamente é isso mesmo, mas apenas de acordo com a narrativa modernista da emancipação. Na narrativa composicionista de conexões, consequências não pretendidas são bem normais - na realidade, as coisas mais esperadas do mundo! (LATOUR, 2011b, p. 25, grifo do autor).

Para este texto - focado mais nos aspectos ontológicos e epistemológicos -, o que mais chama a atenção é o fato de que, como não há evidência de que a multiplicação da Terra esteja a caminho ou mesmo seja possivel, como não há evidência de que mais tecnologia efetivamente contribua para vencer ou pelo menos retardar o colapso climático, o argumento pós-ambientalista é, em última instância, um ato de fé. É uma versão atualizada da fé moderna na tecnologia. Isso evidencia uma vez mais o aspecto metafísico da tecnologia nesse tipo de narrativa. Nem verdadeiro nem falso, utópico.7 Segundo essa fé, a Terra pode ser multiplicada, embora não haja provas nessa direção. Segundo esse credo, a intervenção tecnocientífica vai solucionar o problema que ela mesma criou.

\section{Considerações finais}

A narrativa pós-natureza do antropoceno concebe passado, presente e futuro como um conjunto de associações e conexões entre coletivos diversos, humanos e não humanos. 0 desenvolvimento tecnológico é aquilo que permite ver essa realidade e, mais especificamente, a indiferenciação ontológica entre humano/social e natureza. O argumento neste texto é de que atribuir à tecnologia esse papel significa operar aprioristicamente já no interior do paradigma da técnica. A mediação técnica é tomada não apenas como uma forma de abordar o real, mas a única realmente legítima. Dessa forma, converte-se em premissa inquestionável de toda a civilização. 0 problema é que isso cria a tautologia típica das metafísicas, em que a conclusão já está incluída na premissa. Um conceito de tecnologia que se coloca dessa forma não é capaz de explicar a sua própria especificidade, isto é, o que torna algo tecnológico, porque nele tecnologia é tudo. Nada pode escapar à técnica, nem mesmo a própria técnica. É por essa razão que na narrativa pós-ambientalista do antropoceno tudo precisa necessariamente aparecer como associações e conexões. É por isso que tudo precisa aparecer de forma simétrica, indiferenciada, como função (actante) de uma estrutura (emaranhado) que, somente ela, valida a manifestação das coisas. Daí, finalmente, a Terra comparecer como artefato, como espaçonave Terra. É o clássico dilema das metafísicas. Trata-se, no final das contas, da feitura do real à imagem de uma faceta específica do humano.

É interessante fazer um apontamento sobre este último aspecto. Latour (2014, p. 5) afirma que, no antropoceno, "a ação humana é visivel em todos os lugares - na construção do conhecimento, bem como na produção dos fenômenos que essas ciências são chamadas a registrar". Essa impressão é exatamente o que Heidegger (2000, p. 31) previu que aconteceria com o avanço da tecnologia, isto é, com a universalização do modo técnico de desvelar as coisas: "Desta forma, espalha-se a impressão de que tudo o que o encontra [ao humano] existe apenas na medida em que é sua construção. Essa impressão dá origem, por sua vez, a uma ilusão final: parece que o humano, em todos os lugares e sempre, encontra apenas ele mesmo". Não há mais diferença. Não há mais alteridade. Tudo é o mesmo. Mas isso significa que não são apenas a Terra e a natureza que são reduzidas. $O$ anthropos dessa narrativa também é um humano bastante específico. Só assim, reduzindo-se a uma das suas incontáveis formas de lidar com as coisas, ele pode ver a si mesmo em todos os lugares.

\section{Referências}

ANKER, P. Buckminster Fuller as Captain of Spaceship Earth. Minerva, v. 45, p. 417-434, 2007. ANKER, P. Buckminster Fuller as Captain of Spaceship Earth. Minerva, v. 45. p. 417-434, 2007. https://doi. org/10.1007/s11024-007-9066-7

\footnotetext{
Frase semelhante foi usada na argumentação de Baudrillard (1991, p. 40) sobre reality shows. Apesar de estar em um contexto diferente, ela poderia ser muito bem aplicada para o argumento em questão.
} 
BAMMÉ, A. (org.). Schöpfer der zweiten Natur: Der Mensch im Anthropozän. Marburg: Metropolis, 2014.

BAUDRILLARD, J. Simulations. Nova York: Semiotextle], 1993

BONNEUIL, C. The Geological Turn: Narratives of the Anthropocene. In: HAMILTON, C:; BONNEUIL, C.; GEMENNE, F. (org.). The Anthropocene and the Global Environmental Crisis: Rethinking Modernity in a New Epoch. Nova York: Routledge, 2015. p. 17-32. https:// doi.org/10.4324/9781315743424-2

CRUTZEN, P. Geology of Mankind. Nature, v. 415, p. 23. 2002. https://doi.org/10.1038/415023a

CRUTZEN, P:; STOERMER, E. The "Anthropocene". Global Change Newsletter, v. 41, p. 17-18, 2000

HEIDEGGER, M. Holzwege. Frankfurt: Vittorio Klostermann, 1977. (GA 5)

HEIDEGGER, M. Vorträge und Aufsätze. Frankfurt: Vittorio Klostermann, 2000. (GA 7)

KAGAN, S. Art and Sustainability: Connecting Patterns for a Culture of Complexity. Bielefeld: Transcript Verlag, 2013

KOYRÉ, A. Do mundo fechado ao universo infinito. 4 ed. Rio de Janeiro: Forense Universitária, 2006.

LATOUR, B. Agency at the Time of the Anthropocene New Literary History, v. 45, n. 1, p. 1-18, 2014

LATOUR, B. An Inquiry into Modes of Existence: An Anthropology of the Moderns. Cambridge: Harvard University Press, 2013.

LATOUR, B. Love Your Monsters: Why We Must Care for Our Technologies as We Do Our Children. Breakthrough Journal, n. 2, p. 21-28, 2011b.

LATOUR, B. Network, Societies, Spheres. International Journal of Communication, v. 5, p. 796-810, 2011 a.

LATOUR, B. On Technical Mediation: Philosophy, Sociology, Genealogy. Common Knowledge, v. 3, n. 2. p. 29-64, 1994

LATOUR, B. We Have Never Been Modern. Cambridge: Harvard University Press, 1993

LUCKNER, A. Heidegger und das Denken der Technik. Bielefeld: Transcript, 2008.

MERSCH, D. Die Frage nach der Alterität: Chiasmus, Differenz und die Wendung des Bezugs. In: DALFART, I.; STOELIGER, P. (org.). Hermeneutik der Religionen. Tübingen: Mohr Sibeck, 2007. p. 35-57.

MERSCH, D. Ordo ab chao - Order from Noise. Zurique: Diaphanes, $2013 a$.

MERSCH, D. Turing-Test oder das "Fleisch" der Maschine. In: ENGELL, L.; HARTMANN, F.; VOSS, C. (org.). Körper des Denkens: Neue Positionen der Medienphilosophie. Munique: Wilhelm Fink, 2013b. p. 9-27.
MERSCH, D. Countenance-Mask-Avatar: The "Face" and the Technical Artifact. In: GUNKEL, D. J.; MARCONDES FILHO, C.; MERSCH, D. (org.). The Changing Face of Alterity: Communication, Technology and Other Subjects. Londres: Rowman \& Littlefield International, 2016. p. 17-37.

MICKLE, E. Téchne y técnica, ousia y materia. Hypnos, São Paulo, v. 3. n. 4, p. 18-27, 1998.

PICKERING, A. The mangle of practice: time. agency, and science. Chicago: The University Chicago Press, 1995. https://doi.org/10.7208/chicago/9780226668253.001.0001

RIIS, S. The Symmetry Between Bruno Latour and Martin Heidegger: The Technique of Turning a Police Officer into a Speed Bump. Social Studies of Science, v. 38, n. 2, p. 285-301, 2008. https://doi. org/10.1177/0306312707081379

RÜDIGER, F. Contra o conexionismo abstrato: réplica a André Lemos. Matrizes, São Paulo, v. 9, n. 2, p. 127142, 2015. https://doi.org/10.11606/issn.1982-8160. vgi2p127-142

SHELLENBERGER, M.; NORDHAUS, T. The Death of Environmentalism: Global Warming Politics in a Post-Environmental World. [s.l.]: Breakthrough, 2004.

SLOTERDIJK, P. Wie groß ist "groß"? In: CRUTZEN, P.; DAVIS, M.; MASTRANDEA, M.; SCHNEIDER, S.; SLOTERDIJK, P. (orgs.). Das Raumschiff Erde hat keinen Notausgang: Energie und Politik im Anthropozän. Berlim: Suhrkamp, 2011. p. 93-110.

\section{Tales Tomaz}

Doutor em Ciências pela Escola de Comunicações e Artes da Universidade de São Paulo (ECA/USP, São Paulo, SP, Brasil). Pesquisador na área de economia política da comunicação e das tecnologias no Departamento de Ciências da Comunicação da Universidade de Salzburgo (Áustria).

\section{Endereço para correspondência}

Tales Tomaz

Universidade de Salzburgo (PLUS)

FB Kommunikationswissenschaft

Rudolfskai, 42

5020

Salzburg (AT) 